\title{
PHYSIOLOGY GENERAL CONCEPTS COURSE FOR FIRST YEAR UNDERGRADUATE MEDICAL STUDENTS USING TEAM BASED LEARNING: A DESCRIPTIVE STUDY \\ Sameer Timilsina ${ }^{1,{ }^{*}}$, Poojan Bhusal ${ }^{1}$, Ram Lochan Yadav ${ }^{1}$, Niraj Khatri Sapkota', Md Nazrul Islam ${ }^{1}$ \\ ${ }^{1}$ Department of Physiology, Chitwan Medical College, Bharatpur-5, Chitwan, Nepal
}

Received: 14 Apr, 2020
Accepted: 11 Sept, 2020
Published: 27 Sept, 2020
Key words: Lectures; Medical education; Teaching;
Team-based learning; Undergraduate.
*Correspondence to: Sameer Timilsina, Department
of Physiology, Chitwan Medical College, Bharatpur-5,
\[ \text { Chitwan, Nepal. } \]
Email: timilsina.sameer@cmc.edu.np
Citation
Timilsina S, Bhusal P, Yadav RL, Sapkota NK, Islam
MN. Physiology general concepts course for first
year undergraduate medical students using team
based learning: a descriptive study. Journal of Chit-
wan Medical College.2020;10(33):43-6.

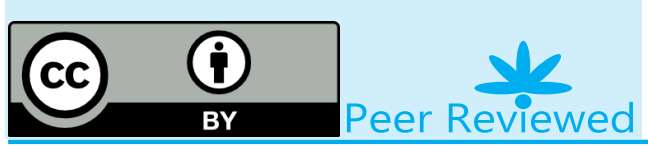

INTRODUCTION

Over the years, medical colleges worldwide have been pioneering innovative teaching-learning methods to bring the best out of their students. These teaching-learning methods have encircled around student-centered learning philosophy aiming to help students achieve a higher level of learning. ${ }^{1}$ Overtime, a number of models have been less effective and large classroom lecture is still the most utilized method. ${ }^{2}$

Team-based learning (TBL) though a new pedagogy to medical education with substantial attention in recent years. ${ }^{3,4}$ It is a team-oriented collaborative process that involves pre-class preparation, in-class individual, and, group readiness assurance testing, and application focused-activities. ${ }^{5}$ The immediate peer and faculty feedback, self-reflection, peer evaluation, and, self-assisted group learning are cornerstones of this strategy. ${ }^{2}$ TBL has been found to improve academic performance, ${ }^{6}$ attendance, ${ }^{7}$ and, ability to work in groups to traditional lecture-based teaching. ${ }^{6,8}$

TBL is not a routinely utilized teaching-learning method in medical colleges across Nepal. Less said, majority of pre-clinical undergraduate students have no exposure to TBL. All ba- sic science subjects including Physiology lecture is delivered in large classrooms either using PowerPoint presentations or whiteboard teaching based on personal teaching preference.

No studies have been conducted in Nepal regarding TBL among medical students. We planned to introduce TBL in teaching general physiology to pre-clinical undergraduate medical students. We aimed to evaluate the perception of TBL using TBLSAI (Team-Based-Learning- Student Assessment Instrument) amongst a cohort of students who are exposed to this methodology for the first time and assess whether students favored TBL over lectures.

\section{METHODS}

Ethical clearance for the study was obtained from Chitwan Medical College- Institutional Review Committee (CMC-IRC). In February 2019, all 100 pre-clinical undergraduate students enrolled at Chitwan Medical College were introduced with TBL as the new teaching-learning method. There were 2 sections of randomly selected 50 students. Each section of 50 students were randomly divided into groups of 7-8 students totaling 7 groups per section. In our study, we started 2-3 TBL sessions per week for 12 weeks instead of the usual lecture-based 
learning to teach general concepts in Physiology abiding by the weekly schedule prepared by the institution. Meanwhile, students were taking traditional lecture-based classes in other pre-clinical subjects. A demographic instrument was administered to the students at the beginning of the semester which included information about age, gender, past educational institute, and, entry type. All 100 students attended TBL sessions some day or another (attendance rate $92.3 \%$ ). We received all 100 filled TBL-SAI but 5 forms were incompletely filled which were excluded from analysis (response rate 95\%).

We followed the standard TBL structure centered around significant problem, same problem, specific choice, and, simultaneous reporting. The students were provided with pre-reading materials which included specified pages and chapters in electronic text-books, videos, and, handouts. At the beginning of each class, individual readiness assurance test (IRAT) was conducted followed by group readiness assurance test (GRAT). The test consisted of 10 questions either alone or a combination of true-false statements, multiple-choice questions (MCQs), and, single answer questions (SAQ's). One-minute time was allotted to answer each question individually and 3 minutes for group answers. Upon completion of IRAT, the same test was repeated in groups to promote group work and establish team consensus. The correct answers were provided and immediate feedback was given following GRAT. Students were allowed to challenge the answers with sufficient evidence. The teacher provided clarifications to the answers and it was followed by mini-lectures particularly when teams experienced difficulty or disputes. Students were then instructed to work in teams in problem-solving activity.

At the end of $12^{\text {th }}$ week, students were instructed to fill in the Team-Based Learning- Student Assessment Instrument (TBLSAI) developed by Mennenga. ${ }^{9}$ It consists of 33 questions with 3 subscales: students accountability ( 8 items), preference for TBL or lecture (16 items) and students satisfaction ( 9 items) with a 5-point Likert scale ranging from strongly disagree to strongly agree. A scoring system developed by Nation et al. which defines an overall score of $>102$ as indicative of preference to TBL was applied to TBL-SAI. ${ }^{10}$ Accountability subscale score $>25$, preference of teaching style subscale score $>49$, and satisfaction subscale score $>28$ indicated students preference towards TBL. ${ }^{10}$

Statistical analysis was done using SPSS-20. Internal consistency of TBL-SAI was assessed using Cronbach's $\alpha$. The numerical values were expressed as mean \pm SD and categorical variables as percentage.

Table 2: Scores according to the dimensions of the TBL-SAI questionnaire

\begin{tabular}{|l|c|c|c|c|}
\hline & Accountability subscale & $\begin{array}{c}\text { Preference of teaching } \\
\text { style subscale }\end{array}$ & $\begin{array}{c}\text { Student satisfaction } \\
\text { subscale }\end{array}$ & Total Score \\
\hline Reference Range & Score $>25$ favors TBL & Score $>49$ favors TBL & Score $>28$ favors TBL & $\begin{array}{c}\text { Score }>102 \text { favors } \\
\text { TBL }\end{array}$ \\
\hline Range & $17-38$ & $42-62$ & $18-41$ & $78-128$ \\
\hline Mean \pm SD & $28.21 \pm 3.89$ & $51.46 \pm 5.10$ & $31.88 \pm 4.35$ & $111.55 \pm 11.05$ \\
\hline
\end{tabular}

\section{RESULTS}

All 100 students attended TBL sessions some day or another (attendance rate 92.3\%). We received all 100 TBL-SAI forms, 5 of which were incomplete and were excluded from analysis (response rate 95\%). The study participants included 67 (70.5\%) males and 28 (29.5\%) females with age ranging between 17-21 years (mean age $=19 \pm 0.94) .67(70.5 \%)$ were Freshmen and $28(29.5 \%)$ were old batches having lost 1 or more years before enrolling in medical school. Seventy-nine (83.2\%) students had previously attended government institutions and the remaining 16/95 (16.8\%) had attended private schools before getting into medical school (Table 1$)$.

Table 1: Socio-demographic characteristics of participants ( $n=95)$

\begin{tabular}{|l|c|}
\hline Socio-demographic characteristics & Frequency (\%) \\
\hline Sex & $67(70.5)$ \\
\hline Male & $28(29.5)$ \\
\hline Female & $67(70.5)$ \\
\hline Entry Type & $28(29.5)$ \\
\hline Freshmen & \\
\hline Old-batch & $16(16.8)$ \\
\hline Past Educational Institute & $79(83.2)$ \\
\hline Government School
\end{tabular}

The internal consistency of TBL-SAI measured using Cronbach's $\alpha$ was 0.728 . Cronbach's $\alpha$ values for accountability subscale was 0.537 , preference of TBL over lecture subscale was 0.319 , and, satisfaction subscale was 0.547 . TBL-SAI was found to be a reliable tool to use among undergraduate medical students in Nepal.

The subscale and total TBL-SAI score were well above the threshold and indicated students favored TBL over traditional lectures (Table 2).

Over $80 \%$ of the students agreed or strongly agreed they felt they had to come prepared and reported having spent time before class to be prepared. A lot of students reported their accountability in their teams learning $(82.6 \%)$ and that they needed to contribute to their teams' learning (62.1\%). Students found TBL to be more engaging as they reported easy distraction during traditional classes ( $74.7 \%$ vs $5.3 \%)$. The majority of students reported enjoying team-based activities (84.2\%) and had a positive attitude towards TBL (90.5\%). A vast majority of students reported having good experiences with TBL (82.4\%). 


\section{DISCUSSION}

Team-based learning collaborative defines TBL "as an evidencebased collaborative learning-teaching strategy designed around units of instructions, known as "modules", that are taught in a three-step cycle: preparation, in-class readiness assurance testing, and application-focused exercise" ${ }^{5}$ TBL encourages student selfreading, holding students accountable for their learning, trigger discussion among teams, and knowledge-application. Our study centered around exploring student's perception of TBL when they were exposed to this new form of teaching-learning activity for the first time.

Analysis of the questionnaire revealed that over $80 \%$ of the students agreed or strongly agreed they felt they had to come prepared and reported having spent time before class to be prepared was encouraging to us. This could be misleading as other subjects were being taught in a traditional lecture system where they are not held accountable in some manner. Also, in this form of heterogeneously grouped students, the formative assessments accounted for final exam scores, so student's accountability was examined right from the beginning. Students reported lecturebased learning to be more distracting than TBL $(74.7 \%$ versus $5.2 \%$ ). As opposed to quick attention loss in traditional lectures, TBL employs group activities which helps maintain focus for a prolonged period. ${ }^{11}$

Over $80 \%$ of the students agreed or strongly agreed that they had a good experience with TBL. We are encouraged with this fact and wish to continue using the same form of teaching-learning methodology or even extending it into other topics. Teams work better and reach the performing stage if they are together for more than 12 weeks, but our study duration was only 12 weeks. Here we cannot speculate the performance and liking towards TBL beyond 12 weeks. A longer study period might overall strengthen the study design.

To the best of knowledge, this is the first study regarding the perception of students to TBL in Nepal. The medical education system over the world has witnessed an improved academic performance of the students, with students even in the lowest academic quartile benefitting with the introduction of TBL. At this stage, it would be premature to conclude, but still, it could be high time for the introduction of TBL into our system. However, in our present study TBL sessions covered limited topics from only one subject of the curriculum. Future long-term studies to assess the impact of replacing traditional lectures with TBL can be conducted.

Studies have reported improvement in student's academic performance and mastery over course content when TBL was used as a teaching-learning method. ${ }^{12,13}$ In the present study, we did not evaluate the academic performance of the students. Further studies are warranted in medical colleges across Nepal to establish such a fact. Also, our present assessment system is based on knowledge-based exams and studies show improvement in such

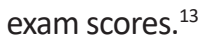

In our study, TBL-SAl suggested students' preference to TBL, but we noted some challenges like students not liking the use of a single teacher, non-coordination with the curriculum, and, lack of preparation time. ${ }^{14} \mathrm{~A}$ large student to faculty ratio established a need for reforming the teaching-learning method and TBL was introduced. So, the challenge of a single facilitator was within the norms of TBL. Here, we would also like to express instructors' lack of experience with this new form. Studies have shown a stronger preference for TBL to the increasing experience of faculties. ${ }^{15}$ Though this new form of teaching-learning activity was well received by the students, the use of experienced and dedicated TBL faculty could further increase student's participation and liking to this form of teaching. ${ }^{6}$ Majority of students reported pre-class preparation, students' feedback of lack of enough preparation time was well received. The inexperience of the faculties and sudden exposure to the vast medical curriculum could explain such a challenge. Medical institutions should think of developing dedicated TBL faculty and implement TBL routinely as a teachinglearning strategy.

\section{CONCLUSION}

Our study suggests supplementing regular traditional lectures with TBL in medical schools across Nepal owing to students' preference of TBL over traditional lectures. With TBL, gaining popularity, the results of this study may be helpful to faculties who are planning to implement TBL in their curriculum. Future studies related to the implementation of TBL with a larger curriculum and longer duration could provide more insight.

\section{CONFLICT OF INTEREST: None}

\section{FINANCIAL DISCLOSURE: None}

\section{REFERENCES:}

1. Michaelsen L, Richards B. Drawing conclusions from the team-learning literature in health-sciences education: a commentary. Teach Learn Med. 2005;17(1):85-8. [DOI]

2. DeJongh B, Lemoine N, Buckley E, Traynor L. Student preparation time for traditional lecture versus team-based learning in a pharmacotherapy course. Curr Pharm Teach Learn. 2018;10(3):360-6. [DOI]

3. Burgess AW, McGregor DM, Mellis CM. Applying established guidelines to team-based learning programs in medical schools: a systematic review. Acad Med. 2014;89(4):678-88. [DOI]

4. Parmelee D, Michaelsen LK, Cook S, Hudes PD. Team-based learning: a practical guide: AMEE guide no. 65. Med Teach. 2012;34(5):e275-e287. [DOI]

5. Team Based Learning Overview [Internet]. Huntington, WV: Team Based Learning Collaborative; 2020 [Cited: 26 March, 2020 ]. Available from: [LINK]

6. Burgess A, Bleasel J, Haq I, Roberts C, Garsia R, Robertson T, et al. Teambased learning (TBL) in the medical curriculum: better than PBL?. BMC Med Educ. 2017;17(1):243. Published 2017 Dec 8. [DOI]

7. Peters $T$, Johnston E, Bolles $H$, Ogilvie C, Knaub A, Holme T. Benefits to Students of Team-Based Learning in Large Enrollment Calculus. PRIMUS 2020;30:211-29. [DOI]

8. Hashmi NR. Team Based Learning (TBL) in undergraduate medical educa- 
tion. J Coll Physicians Surg Pak. 2014;24(8):553-6. [PMID]

9. Mennenga HA. Development and psychometric testing of the Team-Based Learning Student Assessment Instrument. Nurse Educ. 2012;37(4):16872. [DOI]

10. Nation LM, Tweddell S, Rutter P. The applicability of a validated teambased learning student assessment instrument to assess United Kingdom pharmacy students' attitude toward team-based learning. J Educ Eval Health Prof. 2016;13:30. [DOI]

11. Bradbury NA. Attention span during lectures: 8 seconds, 10 minutes, or more?. Adv Physiol Educ. 2016;40(4):509-13. [DOl]

12. Punja D, Kalludi SN, Pai KM, Rao RK, Dhar M. Team-based learning as a teaching strategy for first-year medical students. Australas Med J. 2014;7(12):490-9. [DOI]

13. Koles PG, Stolfi A, Borges NJ, Nelson S, Parmelee DX. The impact of teambased learning on medical students' academic performance. Acad Med. 2010;85(11):1739-45. [DOI]

14. Parthasarathy $P$, Apampa B, Manfrin A. Perception of team-based learning using the team-based learning student assessment instrument: an exploratory analysis within pharmacy and biomedical students in the United Kingdom. J Educ Eval Health Prof. 2019;16:23. [DOI]

15. Davidson LK. A 3-year experience implementing blended TBL: active in structional methods can shift student attitudes to learning. Med Teach. 2011;33(9):750-3. [DOI] 